\section{La reputación de dominio como mecanismo de adquisición del derecho real en la provincia de Corrientes*}

Claim of ownership as a procedure to acquire property rights in the province of Corrientes

\section{Guillermo Gapel Redcozub}

\section{RESUMEN}

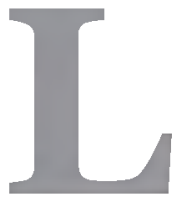

a reputación de dominio es un procedimiento administrativo regulado en la Ley No 6042 "Ley Orgánica de las Municipalidades" de la Provincia de Corrientes que tiene por fin inmediato la adquisición del derecho real de dominio sobre un inmueble que carece de dueño, a favor de un Estado Municipal, con fundamento central en el actual art. 236 del Código Civil y Comercial. En el presente trabajo se describirá su regulación legal, con sus condiciones de procedencia, y se trazan relaciones con otras figuras con las que comparte finalidad, fundamentalmente con la acción declarativa de abandono y con acción de vacancia sucesoria, avanzando con un análisis de sus ventajas y de sus limitaciones, y concluyendo en que el mecanismo no puede emplearse para violar la propiedad privada o comunitaria (mucho menos de los grupos vulnerables) ni para evadir los procesos judiciales que son indispensables para el ejercicio de la correcta atribución de dominio.

Palabras clave: derechos reales; dominio, adquisición de derechos, dominio eminente; procedimiento administrativo.

\section{ABSTRACT}

"Claim of ownership" is an administrative procedure established by Law Number 6042 "Organic Law of Municipalities" of the Province of Corrientes, whose immediate purpose is to allow Municipal States to acquire the right of ownership over vacant land. This procedure is based upon the current article 236 of the Civil and Commercial Code. In this paper we describe and discuss its legal regulation and its relationships with other figures with
Guillermo Gapel Redcozub guillermogapel@gmail.com

Facultad de Derecho y Ciencias Sociales y Políticas

Universidad Nacional del Nordeste ARGENTINA

COMO CITAR ESTE ARTÍCULO Gapel Redcozub, G. (2021). La reputación de dominio como mecanismo de adquisición del derecho real en la provincia de Corrientes. Revista de la Facultad de Ciencias Económicas, 26(1), 115 - 125. http://dx.doi.org/10.30972/rfce.2615037

\section{(@) $\Theta \Theta \Theta$}

https://creativecommons.org/licenses/by-nc-nd/4.0/ Revista de la Facultad de Ciencias Económicas ISSN $1668-6357$ (formato impreso) ISSN 1668-6365 (formato digital) por Facultad de Ciencias Económicas Universidad Nacional del Nordeste (UNNE) Argentina se distribuye bajo una Licencia Creative Commons Atribución - No Comercial - Sin Obra Derivada 4.0 Internacional.

\footnotetext{
"Trabajo realizado en el marco del proyecto de investigación "Regularización dominial en el NEA:
} marco jurídico y políticas públicas"- aprobado por la Secretaría General de Ciencia y Técnica - UNNE. 
which it shares its purpose, mainly with the declarative action of abandonment and with the action of succession vacancy, advancing with an analysis of its advantages and its limitations, and concluding that the mechanism cannot be used to violate private or community property (much less of vulnerable groups) or to evade the judicial processes that are essential for the correct attribution of ownership.

Keywords: property rights; claim of ownership; acquisition of property; eminent domain; administrative procedure.

\section{COMENTARIOS INTRODUCTORIOS}

La reputación de dominio es un procedimiento administrativo que tiene por fin inmediato la adquisición del derecho real de dominio sobre un inmueble, a favor de un Estado Municipal, con fundamento central en una norma atributiva de propiedad prevista en la legislación civil.

Está regulado en el artículo 172 de la Ley Nº 6042 "Ley Orgánica de las Municipalidades" de la Provincia de Corrientes y se caracteriza por llevarse a cabo enteramente en sede administrativa. ${ }^{1}$

En el presente trabajo se describirá su regulación legal, con sus condiciones de procedencia, y se trazarán relaciones con otras figuras con las que comparte finalidad, principalmente con la acción declarativa de abandono y con la acción de vacancia sucesoria, concluyendo con un análisis de sus ventajas y limitaciones.

\section{PRESUPUESTOS DEL MECANISMO}

El procedimiento de reputación de dominio opera "cuando se trate de inmuebles considerados de propiedad privada municipal respecto de los cuales se carezca de títulos y se considere procedente la aplicación de la norma del art. 2.342 del Código Civil como fundamento del dominio [...]".

Vale decir entonces que este trámite únicamente recae sobre bienes inmuebles y no puede emplearse para la adquisición de muebles. Al no distinguirse entre las distintas clases de cosas inmuebles previstas en el ordenamiento- por su naturaleza (2.314 C.Civ., hoy 225 CCC) o por accesión (2.315 C.Civ., hoy 226 CCC)-, cabe suponer que ambas pueden ser objeto de la norma y que este procedimiento permite la adquisición simultánea y conjunta

${ }^{1}$ No ha trascendido que otras jurisdicciones provinciales cuenten con procedimientos similares. 
del suelo y de lo plantado o edificado, lo que por otra parte es consistente con el principio superficies solo cedit. ${ }^{2}$

Es de vital importancia destacar que sobre estos inmuebles el municipio debe carecer de títulos. La voz título tiene múltiples acepciones en el derecho argentino, las que van desde cualquier tipo de antecedente jurídico que habilite la adquisición de derechos reales hasta la referencia a un cierto tipo particular de acto jurídico denominado "título suficiente" (que debe reunir recaudos de fondo, de forma y de idoneidad y que está regulado en el art. 1892 del CCC), sin olvidar la acepción de uso cotidiano que asimila el vocablo título al del soporte instrumental o documento en el que se asienta un derecho.

¿En qué sentido se utiliza la palabra "título" en el art. 172 de la Ley No 6.042 ?

Parece razonable considerar que la norma exige la ausencia de cualquier tipo de acto jurídico que pueda dar sustento a la pretensión municipal, provenga este del derecho privado o del derecho público. Así, por ejemplo si existiese una donación privada a favor del municipio que no se ha perfeccionado, una compraventa mediante boleto que no se ha elevado a escritura pública (por incomparecencia o renuencia del vendedor), o la adquisición por posesión veinteañal llevada a cabo por el municipio, entre otros antecedentes posibles, el estado local deberá iniciar los procesos judiciales civiles correspondientes (de cumplimiento de contrato, de escrituración, o de prescripción adquisitiva, respectivamente) y no podrá acudir a este mecanismo de reputación.

De la misma manera, cuando su pretensión se origine en actos administrativos o normas provinciales o nacionales mediante las cuales se les transfieran inmuebles destinados a uso privado por parte del municipio, y resulte necesario agotar actuaciones incompletas o subsanar vicios para perfeccionar la transmisión de posesión y dominio, los municipios deberán dar curso a las vía administrativas, primero, y en todo caso al reclamo contencioso-administrativo pertinente, mas no podrán recurrir a la figura de la reputación.

Lo señalado se sustenta en la ostensible extraordinariedad de este mecanismo de adquisición, lo que exige que opere en forma restrictiva y sea subsidiario respecto de los procedimientos de naturaleza judicial, en los que se tiende a resguardar con mayor firmeza la contradictoriedad y la imparcialidad, y por ende, el derecho de propiedad del particular eventualmente afectado. ${ }^{3}$

Por último, se exige que el municipio funde su pretenso derecho real en una norma específica de la legislación civil que es atributiva de dominio: el art. 2.342 del C.Civ. (vigente al momento de la sanción de la Ley No 6.042) disponía que:

\footnotetext{
2 "La máxima superficies solo cedit enuncia la accesión al suelo de todo aquello que se encuentra superpuesto al mismo. Como consecuencia de este principio el dominus soli se convierte en propietario de lo construido o plantado sobre el suelo. Superficies solo cedit determina que todo lo que está físicamente unido al suelo jurídicamente también se considere unido." (Zaera García, 2008, p. 1009).

${ }^{3}$ En relación al carácter restrictivo con que deben aplicarse los mecanismos excepcionales de adquisición del dominio y refiriéndose puntualmente a la figura de la usucapión, Mariani subraya que se debe ser muy estricto en la apreciación de la prueba que hace a la procedencia de la acción (2010, p. 371).
} 
Son bienes privados del Estado general o de los Estados particulares:

$1^{\circ}$ Todas las tierras que estando situadas dentro de los límites territoriales de la República, carecen de otro dueño; [...]

$3^{\circ}$ Los bienes vacantes o mostrencos, y los de las personas que mueren sin tener herederos, según las disposiciones de este código; [...]

En relación al primer inciso, Llambías (1997, p. 215) explica que en la época colonial los reyes españoles y portugueses adjudicaron grandes extensiones de tierra a los conquistadores, como recompensa por sus esfuerzos; quedando dentro del patrimonio de la Corona todas las tierras restantes. Estas últimas, luego de la emancipación política, pasaron al Estado nacional o provincial.

Este sería, entonces, el fundamento histórico de la incorporación de la norma como factor atributivo de dominio privado a favor de los estados. Kiper afirma que sobre estas tierras el Estado tiene un derecho originario, el que además se presume con carácter iuris tantum (2004, p. 124). Cabe aclarar que para este autor la señalada norma sólo beneficia al Estado Nacional y al Provincial, pero no a los Municipios puesto que estos no tienen dominio originario y lo deben adquirir por transferencia de los restantes niveles estaduales. ${ }^{4}$

Sobre el inciso tercero, $y$ en referencia a los inmuebles, Llambías (1997, p. 215) manifiesta que allí se contemplan las categorías de bienes vacantes, que son los de propietario desconocido; y de bienes de personas fallecidas sin herederos (que serían también una suerte de bienes sin propietarios conocidos): ambas clases terminan unificándose en la práctica bajo el mismo de nombre de "bienes vacantes". En uno y otro caso, sostiene Kiper (2004, p. 125), suelen tratarse de cosas abandonadas, reafirmando además que estas cosas deben pasar al Estado nacional o provincial, como titular de lo que se denomina dominio eminente. ${ }^{5}$

En resumen, concluye Llambías:

La diferencia existente entre los bienes de los incs. $1^{\circ}$ y $3^{\circ}$ del art. 2342 , radica en que los primeros nunca han salido del patrimonio del Estado, mientras los últimos han pasado a poder de los particulares, pero por falta de titular actual son atribuidos al Estado (1997, p. 215).

La derogación y reemplazo del Código Civil por el nuevo Código Civil y Comercial (CCC) - producida en el año 2015- nos obliga a actualizar y repensar la remisión de la ley provincial. Para ello debemos dirigir la atención al artículo 236 que es la norma que juega un rol equivalente en el nuevo ordenamiento.

\footnotetext{
${ }^{4}$ Este mismo autor reconoce que la exclusión que postula respecto de los Municipios es contraria a las opiniones de Salvat y Lafaille en la materia. De seguir a Kiper, entonces, no se admitiría que los estados locales puedan adquirir inmuebles con base en el art. 2342 inc. 1 del C.Civ.

${ }^{5}$ De sus afirmaciones cabe concluir que estos bienes vacantes no pueden pasar directamente a los Municipios, por lo que los estados locales tampoco podrían adquirir inmuebles conforme el art. 2342 inc. 3 del C. Civ., sino que necesitarían de alguna previsión adicional dictada por el Estado Nacional o Provincial que legitime sus pretensiones.
} 
El art. 236 CCC dispone que

Pertenecen al Estado nacional, provincial o municipal, sin perjuicio de lo dispuesto en leyes especiales:

a) los inmuebles que carecen de dueño [...];

Decimos que estas normas (2342 C.Civ. y 236 CCC) desempeñan un papel equivalente porque en ambos Códigos operan como "dispositivo de cierre del sistema de propiedad", evitando la proliferación de cosas valiosas "sin dueño" y la consolidación de estas situaciones en el tiempo, lo que fomentaría la improductividad o subexplotación de los recursos y disminuiría los activos y los ingresos de los Estados.

Luce razonable que un sistema jurídico cuente con un mecanismo de atribución por defecto o subsidiario de ciertos derechos que considera esenciales para su normal funcionamiento, como lo son los derechos reales (en especial sobre inmuebles), un esquema que permita ir saneando las vacancias de origen (por la existencia de tierras sin asignaciones expresas a particulares en los diferentes momentos constitutivos del Estado) y también las que se vayan produciendo a lo largo de los años (porque las personas fallecen sin herederos, por ejemplo, y entonces el derecho sucesorio o régimen de transmisión mortis causa precisa de pautas de asignación para tales casos).

En general, los doctrinarios que han formulado las primeras interpretaciones de este artículo en el nuevo Código Civil y Comercial no hallan diferencias sustanciales entre el criterio de adjudicación fijado por el nuevo art. 236 y el del anterior art. 2342. Así se han expresado Peralta Mariscal (2014, p. 524), Smayevsky, Penna y Bracaglia Solá (2014, p. 775), Gurfinkel de Wendy (2016, p. 94) y Tobías (2016).

Para ellos, el citado art. 236 a priori produciría la misma regla de atribución de derechos que su antecesor, correspondiéndole al Estado el dominio privado de los inmuebles que no tengan dueño.

Ahora bien, el antecedente normativo de la regla y las explicaciones doctrinarias que se brindan en su justificación permiten distinguir que al estado de "inmueble actualmente sin dueño" se puede arribar mediante diversas vías: cuando desde la conformación política del Estado la cosa jamás tuvo dueño, es decir, nunca ingresó al patrimonio de una persona; o cuando sí lo hizo pero en algún momento la transmisión dominial se cortó por inexistencia de sucesores o abandono y el bien se mantuvo en dicha condición (vale decir, no fue "reapropiado" mediante usucapión).

Por lo tanto, la descripción "inmuebles que carecen de dueño" del art. 236 CCC reúne tres supuestos jurídicos disímiles:

a) La cuestión del inmueble abandonado

Para Salvat el abandono de una cosa inmueble, aunque jurídicamente factible, será sumamente raro en la práctica. Para su procedencia se debe exigir el concurso de dos condicio- 
nes: $1^{\circ}$ ) que sea voluntario, y $2^{\circ}$ ) que sea hecho por persona capaz (1962, p. 315). Vázquez agrega que, además de voluntario, el abandono debe ser expreso, añadiendo que la renuncia a los derechos no se presume conforme lo dispone el art. 948 del CCC. Cuando recae sobre un inmueble debe formalizarse por escritura pública, pasando la cosa al dominio privado del estado (2020, p. 195).

Por su parte Borda parece coincidir con Vázquez, sosteniendo que solo sería posible afirmar que existe abandono de un inmueble cuando el dueño ha manifestado expresamente su voluntad de hacerlo (1978, p. 342).

Scotti (1984) remarca que el simple abandono material de un inmueble por parte de un particular no ocasiona pérdida de dominio y transferencia lisa y llana del bien al Estado, sino que es preciso que tenga lugar un "abandono calificado" comprobado judicialmente. Esto halla sustento en el carácter perpetuo del derecho de dominio, que estaba consagrado en el art. 2510 del Código Civil y mantiene su vigencia en el art. 1942 del CCC.

Agrega que:

"Para obtener la declaración de vacancia será preciso, por tanto, la promoción de una acción judicial tendiente a la acreditación [...del abandono], dado que no es posible admitir que en sede administrativa y por la sola valoración de órganos estatales se juzgue abandonado el inmueble y extinguido el dominio precedente" (Scotti, p. 978).

La intención de abandonar el bien, indica el autor a partir del estudio de precedentes jurisprudenciales, puede inferirse de la falta de pago de tributos por un lapso suficientemente prolongado como para entender que la omisión no es accidental ni fruto de precariedades económicas provisorias, de la ausencia absoluta de actos posesorios, y de la falta de vigilancia para el resguardo de intrusos, entre otras. La voluntad de abandono también podría deducirse indirectamente del silencio mantenido por el propietario ante las citaciones que se le cursaran para que manifieste la subsistencia de su interés en la cosa, estando fehacientemente anoticiado de ellas.

Todas estas evidencias pueden perfectamente recogerse en el marco de un expediente administrativo y acompañarse luego como prueba en la acción declarativa de vacancia.

En resumen, para que pueda considerarse que un inmueble se encuentra en estado de abandono y en razón de ello se pueda atribuir su dominio al Estado se requiere: i) la voluntad expresa en tal sentido del propietario capaz, plasmada en escritura pública; o ii) la calificación de abandono obtenida en sede judicial, mediante juicio contradictorio en el cual se logre acreditar suficientemente la falta de cualquier mínimo interés del titular en la conservación del derecho real.

b) La cuestión del inmueble vacante por inexistencia de sucesores

En nuestro ordenamiento jurídico la muerte real o presunta de una persona causa la apertura de su sucesión y la transmisión de su herencia a las personas llamadas a sucederle por el testamento o por la ley (art. $2277 \mathrm{CCC}$ ). Cuando se produce el fallecimiento de una persona sin que ningún sucesor legítimo o testamentario haya acreditado su vocación, o las disposiciones 
testamentarias no cubran la totalidad de la herencia y no existen herederos legítimos, los bienes se reputan vacantes y se le atribuyen al Estado (Lloveras, Orlandi y Faraoni, 2015, p. 178).

Este fenómeno de vacancia incluye los supuestos de inexistencia total de herederos (legítimos o testamentarios), de pretendientes que no logran justificar sus títulos, y los casos de herederos que sí existen pero que no se presentan a la sucesión o prefieren renunciar a sus derechos.

Frente a estas situaciones se abre la posibilidad de que el Estado solicite la declaración judicial de vacancia para hacerse del dominio de los bienes que pertenecían al causante, trámite que se rige por las previsiones de los arts. 2441 a 2443 del CCC.

A los fines del presente trabajo bastará con señalar que, encontrándose un inmueble dentro del patrimonio de una persona fallecida (o presuntamente fallecida), se prevé un mecanismo específico de atribución a favor del Estado y que debe cumplirse en sede judicial.

La determinación acerca de cuándo el dominio sobre un inmueble ha ingresado al patrimonio de una persona, y por lo tanto integra la masa sucesoria, remite necesariamente a las pautas de adquisición y oponibilidad de derechos reales, es decir, a la constatación de que la persona cuenta con título y modo suficiente y de que ha inscripto el título en el Registro correspondiente (arts. 1892 y 1893 CCC), o de que lo ha adquirido mediante usucapión (con sentencia inscripta), o de que ha operado a su favor una transferencia mortis causa.

Ello implica, en términos prácticos, que toda vez que un inmueble cuente con inscripción registral, aunque esta revista una antigüiedad considerable, será razonable suponer que estamos ante un bien que ha ingresado a la cadena de transmisiones dominiales regulares, y que por lo tanto, si el Estado considera que esta cadena se ha cortado por inexistencia de sucesores debe acudir al procedimiento judicial específicamente previsto para canalizar su pretensión.

c) La cuestión de los inmuebles que jamás han tenido dueño conocido.

A diferencia de los supuestos anteriores, aquí estamos en presencia de bienes que nunca han ingresado a un patrimonio particular, sino que ab initio pertenecen al Estado por manifestación de su dominio eminente. Normalmente serán inmuebles que no cuentan con registros dominiales y con frecuencia ni siquiera catastrales.

Esto no quiere decir que sobre dichas tierras no puedan existir pretensiones absolutamente legítimas, como podría ser la de reconocimiento de la propiedad comunitaria de las tierras que tradicionalmente ocupan los "pueblos indígenas argentinos" (art. 75 inc. 17 de la Constitución Nacional), o de reconocimiento de las posesiones ancestrales de tierras rurales que revisten muchas veces las familias de campesinos, familias que nunca han logrado acceder a los títulos formales de un dominio que han adquirido por usucapiones operadas muchos años atrás. Entra aquí a tallar la cuestión de la grave situación de vulnerabilidad socioeconómica y de las enormes dificultades en el acceso a la justicia que padecen determinadas comunidades o sectores de la población, lo que los termina privando de los instrumentos indispensables para la acreditación y eficaz salvaguarda de sus derechos de propiedad sobre inmuebles. 
Sin perder de vista lo señalado precedentemente, para los inmuebles que jamás han tenido dueño conocido la reputación de dominio ofrece un mecanismo saneatorio de títulos que puede resultar útil por su celeridad y economía.

En síntesis: es fundamental tener presente a los efectos de la correcta delimitación de este supuesto que la carencia de datos registrales en relación a la propiedad de un inmueble, por más absoluta que sea, no permite su categorización directa de "inmueble que jamás ha tenido dueño conocido" y su atribución inmediata al pretenso amparo del art. 236 del CCC. Por el contrario, se impone al Estado el deber de llevar adelante las constataciones necesarias para asegurar que su pretensión no lesiona legítimos derechos de los ocupantes, máxime cuando estos pertenecen a grupos desaventajados, so pena de tergiversar el sentido y la finalidad del citado artículo empleándolo como instrumento de despojo y apropiación indebida.

\section{3. ¿CÓMO ES EL PROCEDIMIENTO DE REPUTACIÓN?}

Si un Municipio detecta que se halla ante un "posible caso" de atribución por reputación, se debe proceder a la mensura y deslinde del inmueble, con citación de linderos y aprobación de las operaciones por el Departamento Ejecutivo Municipal (a cargo del Intendente) mediante Resolución dictada al efecto.

Entendemos que estas operaciones deben sujetarse al Decreto $\mathrm{N}^{0} 2283$ que reglamenta la elaboración de mensuras. Allí se clasifica a esta mensura como "simplemente particular" (art. 13) y se exige que cuente con la aprobación de la Dirección General de Catastro (art. 70).

Luego se deben publicar edictos en el Boletín Oficial de la Provincia y un diario local o de mayor circulación en la localidad, durante diez días (se pueden hacer en ese lapso un mínimo de cinco publicaciones día por medio), y se debe dar difusión de estos avisos en la sede comunal y todo edificio público existente en la localidad por el mismo plazo, haciendo saber que la Municipalidad reputa de su dominio, con arreglo al art. 2.342 del Código Civil el inmueble respectivo, y llamando a terceros que se consideren con derecho a que formulen sus reclamos dentro del término de publicación, bajo apercibimiento de tener por firme el dominio municipal sobre el inmueble determinado.

A continuación se certifica que ha vencido el plazo de las publicaciones, y si se han registrado reclamos. Para el supuesto de que no se hayan producido reclamos considerados admisibles, el Departamento Ejecutivo Municipal dictará una Resolución declarando al inmueble deslindado de propiedad de la municipalidad en los términos del art. 2.342 del Código Civil. Las actuaciones administrativas conformarán el título en sentido instrumental, el que debe inscribirse en el Registro de la Propiedad Inmueble y en la Dirección General de Catastro. 
Como puede observarse, la regulación de la figura es un tanto acotada y adolece de algunas imprecisiones o insuficiencias significativas, entre las que se destacan:

i) Ausencia de parámetros objetivos para la detección de "casos posibles", lo que permite una discrecionalidad excesiva en la apertura de los procedimientos. Podrían incorporarse pautas como la omisión de pago de tributos por periodos considerables y determinados y un a priori ostensible estado de abandono del inmueble como elementos tipificantes para originar el trámite;

ii) Entre los recaudos de las etapas iniciales tampoco se consigna expresamente la necesidad de que se realicen constataciones oficiales para determinar en grado fehaciente el estado del inmueble, si cuenta con ocupantes y en qué carácter, y qué sucedería con el procedimiento ante la eventualidad de una ocupación (que puede obedecer a múltiples causas);

iii) Si bien los mecanismos de publicidad seleccionados (edictos en boletín oficial y diarios, y avisos en la sede comunal) son los habituales cuando los destinatarios (o sus domicilios) son desconocidos, dada la gravedad del apercibimiento ("tener por firme el dominio municipal") resulta conveniente reforzar el aspecto publicitario del mecanismo de reputación. Esto puede lograrse mediante la orden de colocación de cartelería directamente en el inmueble y/o con citaciones a los domicilios que puedan tener registrados los eventuales interesados en las constancias municipales, así como otorgando plazos más prolongados para la comparecencia de los interesados.

iv) No se establece en qué debe consistir cada reclamo de los particulares interesados (su contenido o justificación), ni específicamente qué debería probar el reclamante para que su planteo pueda ser considerado "admisible" por parte del Municipio, y con ello se cierre el procedimiento de reputación (o se lo recalifique y se lo redirija hacia otros mecanismos de adquisición a favor del Municipio).

\section{CONCLUSIONES}

Sin perjuicio de las críticas procedimentales señaladas, cuyo ajuste podría contribuir a la mejora cualitativa del dispositivo de atribución de dominio por reputación, resulta fundamental tener presente a qué tipo de supuestos puede aplicarse el mecanismo administrativo y a cuáles no. El Municipio no puede emplearlo en los casos en que el inmueble carezca de dueño por abandono meramente material o simple inexistencia de sucesores conocidos, debiendo en estas situaciones acudir a las vías judiciales pertinentes para acreditar que se ha configurado el abandono u obtener la declaración de vacancia. Es en el marco de estos procesos contradictorios en donde el Estado local debe hacer valer el art. $236 \mathrm{CCC}$, dándose todas las posibilidades de defensa y las debidas garantías a los eventuales afectados.

Asimismo, en los supuestos de inmuebles que jamás han tenido dueño conocido, las actuaciones administrativas de reputación encuentran un límite frente a ocupantes que oponen 
posesiones (sobre todo cuando sean consolidadas en el tiempo) o plantean el reconocimiento de derechos de propiedad como los del art. 75 inc. 17 C.N., debiendo el Municipio en estos casos continuar con el reclamo de sus pretensiones en sede judicial si así lo desea.

En definitiva, el mecanismo de reputación de dominio puede aplicarse legítimamente y será una herramienta válida para la adquisición del derecho real siempre y cuando se mantenga dentro de los carriles indicados, pero no puede emplearse para violar la propiedad privada o comunitaria (mucho menos de los grupos vulnerables) ni para evadir los procesos judiciales que son indispensables para el ejercicio de la correcta atribución del dominio de un inmueble.

\section{REFERENCIAS BIBLIOGRÁFICAS}

Borda, G. (1978). Tratado de Derecho Civil. Derechos Reales. Editorial: Abeledo Perrot.

Gurfinkel de Wendy, L. (2016). Derechos Reales. Editorial: Abeledo Perrot.

Kiper, C. (2004). Código Civil comentado. Derechos Reales. Editorial: Rubinzal Culzoni.

Llambías, J. J. (1997). Tratado de Derecho Civil. Parte General. Editorial: Abeledo Perrot.

Lloveras, N., Orlandi, O. y Faraoni, F. (2015). Comentario al artículo 2241. En M. Herrera, G. Caramelo y S. Picasso (Dirs.). Código Civil y Comercial comentado (p. 178, Tomo VI). Infojus. Mariani, M. (2010). Derechos Reales. Editorial: Zavalía.

Peralta Mariscal, L. (2014). Comentario al art. 236. En J. C. Rivera y G. Medina (Dirs.). Código Civil y Comercial de la Nación comentado (Tomo I). La Ley.

Salvat, R. (1962). Tratado de Derecho Civil Argentino. Derechos Reales. Editorial: Tipográfica Editora Argentina.

Scotti, E. O. (1984). Adquisición del dominio de inmuebles por vacancia o abandono. El Derecho, Tomo 108, 975-979.

Smayevsky, M., Penna, M. y Bracaglia Solá, A. (2014). Comentario al art. 236. En R. Lorenzetti (Dir.). Código Civil y Comercial de la Nación comentado (Tomo I). Editorial: Rubinzal Culzoni.

Tobías, J. (2016). Comentario al art. 236. En J. Alterini (Dir.). Código Civil y Comercial de la Nación comentado (Tomo 2). Editorial: La Ley. 
Vazquez, G. (2020). Derechos Reales. Editorial: La Ley.

Zaera García, A. (2008). Superficies solo cedit. En Anuario da Facultade de Dereito da Universidade da Coruña, Número 12, pp. 1007-1018. Disponible en:

https://core.ac.uk/download/pdf/61901294.pdf

\section{CURRICULUM VITAE}

\section{Guillermo Gapel Redcozub}

Abogado y Licenciado en Economía (Universidad Nacional del Nordeste). Especialista en Docencia Universitaria (Universidad Nacional del Nordeste). Master of Laws (Harvard Law School, Estados Unidos). -Fue becario Fullbright Master. Profesor Titular Regular de Derechos Reales en la Facultad de Derecho de la Universidad Nacional del Nordeste (Argentina). Ha integrado equipos de investigación en diferentes organismos, contando con publicaciones en revistas científicas de Argentina, Colombia, Chile y España.

guillermogapel@gmail.com 